\section{KINETIC STUDY OF COAL AND BIOMASS CO- PYROLYSIS USING THERMOGRAVIMETRY}

\author{
Ping Wang $^{a}$, Sheila W. Hedges ${ }^{a}$, Kiran Chaudhari ${ }^{b}$, and Richard \\ Turton $^{b}$
}

${ }^{a}$ DOE/NETL, 626 Cochrans Mill Road, Pittsburgh, PA 15236, USA

${ }^{\mathrm{b}}$ Department of Chemical Engineering, West Virginia University, WV 26506, USA

\section{Introduction}

The major driving force for adding biomass in coal utilization is to utilize renewable energy resources and reduce net coal $\mathrm{CO}_{2}$ emission. Co-firing (blend of biomass with coal combusted in air) as a co-utilization technology has been successfully demonstrated in numerous power plants and has shown reduction of $\mathrm{CO}_{2}$ emission ${ }^{1}$. A life cycle (LC) analysis concluded that co-firing of Illinois No. 6 coal and forest residue (10\% heat) reduces the LC greenhouse gas (GHG) emission by $6.6 \%{ }^{2}$. Simulation tools that can be used to predict behaviors of coal and biomass blends in co-utilization and to optimize system designs and operation are a potentially cost effective way to assist further technology development. Kinetic models are needed for blends of coal and biomass for devolatilization/pyrolysis, gasification and combustion processes. Thermogravimetry (TGA) has been widely used to obtain kinetics parameters of solid fuel thermal processes using non-isothermal methods at one or multiple heating rates $^{3}$. Biomass mainly consists of hemicelluloses, cellulose, and lignin and it has different composition with coal. Biomass pyrolysis kinetic models are mainly developed based on the mechanism of three independent parallel first order reactions of three pseudocomponents ${ }^{4}$. Iso-conversional and multi-heating rate methods are widely used in solid thermal decomposition kinetics study ${ }^{3}$. Using the methods on the co-pyrolysis is challenging due to inherent heterogeneity of both biomass and coal, and to the complexity of copyrolysis of these blends. The objectives of this study are to investigate thermal behavior of coal and biomass blends in inert gas environment at low heating rates and to develop a simplified kinetic model using model fitting techniques based on TGA experimental data.

\section{Materials and Methods}

Powder River Basin (PRB) sub-bituminous coal and pelletized southern yellow pine wood sawdust with less than $1 \%$ bark and without additional chemicals were received from DOE National Carbon Capture Center managed by Southern Company in Wilsonville, Alabama. These materials were ground then sieved and the fraction between 100 to $300 \mu \mathrm{m}$ is used in this study. The proximate and ultimate analysis of the coal and wood samples were listed in Table 1.

Table 1. Proximate and Ultimate analysis of Powder River Basin (PRB) Sub-bituminous Coal and Wood

\begin{tabular}{lcccccc}
\hline & \multicolumn{5}{c}{ Proximate analy sis (\% dry basis) } \\
\cline { 2 - 7 } & Volatile matter & Fixed carbon & Ash \\
\hline PRB coal & 46.2 & \multicolumn{2}{c}{47.2} & 6.6 \\
Wood & 85.1 & \multicolumn{6}{c}{14.3} & \multicolumn{2}{c}{0.6} \\
\hline & \multicolumn{5}{c}{ Ultimate analy sis (\% dry basis) } \\
\cline { 2 - 7 } & $\mathrm{C}$ & $\mathrm{H}$ & $\mathrm{N}$ & $\mathrm{S}$ & ash & O (diff) \\
\hline PRB coal & 66.21 & 4.2 & 1.21 & 0.48 & 6.6 & 21.3 \\
Wood & 48.84 & 5.78 & 0.38 & 0.15 & 0.6 & 44.21 \\
\hline
\end{tabular}

Thermal behavior and co-pyrolysis kinetics of the coal, wood, and blends having 10 and 20\% (wt) of wood were studied using a thermogravimetric analyzer (TGA) (Perkin Elmer Pyris 1). The samples ( 10mg) were first heated up to $100^{\circ} \mathrm{C}$ and held for $20 \mathrm{~min}$ to dry them. A non-isothermal method with low heating rates of 10, 20, and $50^{\circ} \mathrm{C} / \mathrm{min}$, respectively, was selected. The samples were heated up to $1000^{\circ} \mathrm{C}$ and held for 5-20 min in dry $\mathrm{N}_{2}$ with a total flow rate of approximately $125 \mathrm{ml} / \mathrm{min}$. The experiments were performed in triplicate (quadruplicate or more for coal and wood blends) to assess their reproducibility.

\section{Results and Discussion}

Thermal behavior of coal, wood and their blends at low heating rates in pyrolysis. Figures 1 and 2 show the weight fraction remaining $\left(\mathrm{m} / \mathrm{m}_{\mathrm{o}} \%\right.$ where $m_{0}$ is initial dry weight of the feedstock sample at $100^{\circ} \mathrm{C}$ ) as a function of temperature (TG), and the weight loss rate (DTG) of coal, $20 \%$ wood in blend, and wood at $50^{\circ} \mathrm{C} / \mathrm{min}$ heating rate during pyrolysis. Coal pyrolysis has higher final residue $58.4 \pm 0.5 \mathrm{db} \%$ compared to wood $16.7 \pm 1.3 \mathrm{db} \%$ (figure 1). DTG curve of coal has a broad peak with temperature of maximum weight loss rate $\mathrm{T}_{\max }=475 \pm 2{ }^{\circ} \mathrm{C}$ and lower maximum weight loss rate $\mathrm{R}_{\max }=0.13 \% / \mathrm{s}$ compared to wood which has a sharp peak with a shoulder in DTG with lower $\mathrm{T}_{\max }=395 \pm 0.5^{\circ} \mathrm{C}$, and higher $\mathrm{R}_{\max }=0.7 \% / \mathrm{s}$. Blend with $20 \%$ wood has two peaks with $\mathrm{T}_{\text {onset }}=$ $397 \pm 1^{\circ} \mathrm{C}$ close to wood and $\mathrm{R}_{\max }=0.24 \% / \mathrm{s}$ higher than coal.

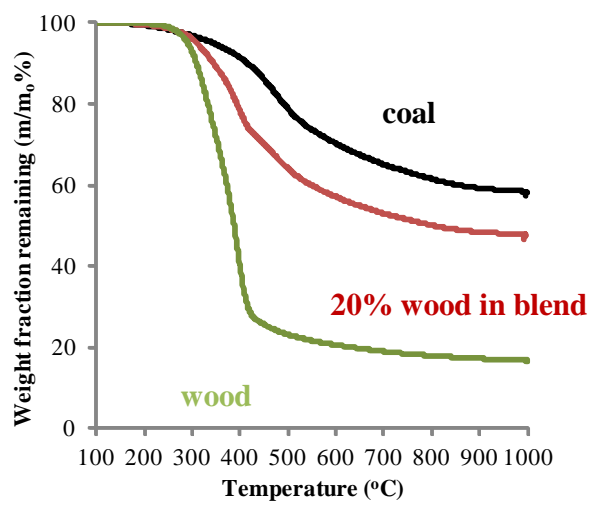

Figure 1. Weight fraction remaining of coal, 20\% wood in blend, and wood vs temperature at $50^{\circ} \mathrm{C} / \mathrm{min}$ heating rate during pyrolysis.

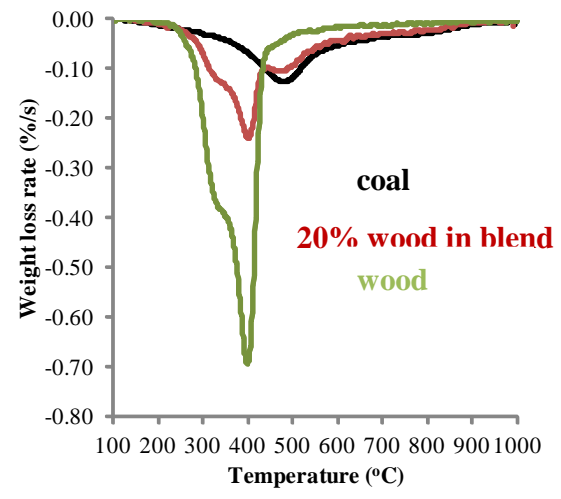

Figure 2. Weight loss rate of coal, 20\% wood in blend, and wood vs temperature at $50^{\circ} \mathrm{C} / \mathrm{min}$ heating rate during pyrolysis.

Figures 3 and 4 show TG) and DTG of 20\% wood in blend at heating rates of 10,20 and $50^{\circ} \mathrm{C} / \mathrm{min}$ during co-pyrolysis. As heating rates increase, weight loss rates increase (figure 4) but $\mathrm{T}_{\max }$ and weight fraction remaining are not significantly different (figure 3 and 
table 2). This absence of clear trends is likely due to the high heterogeneity of wood and coal, and the relatively small difference between heating rates.

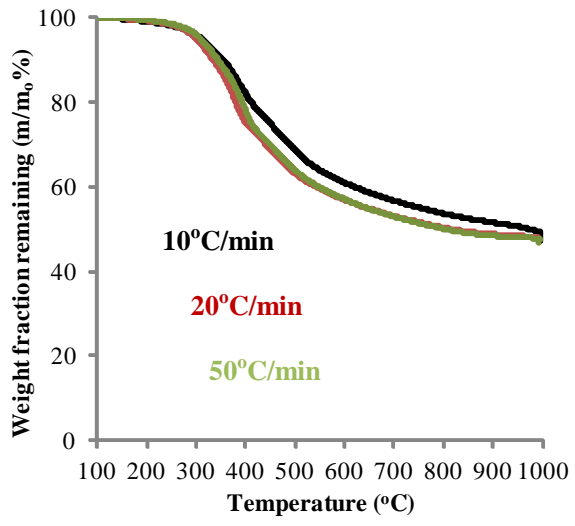

Figure 3. Weight loss of $20 \%$ wood in blend vs temperature at heating rates of 10,20 and $50^{\circ} \mathrm{C} / \mathrm{min}$ during co-pyrolysis.

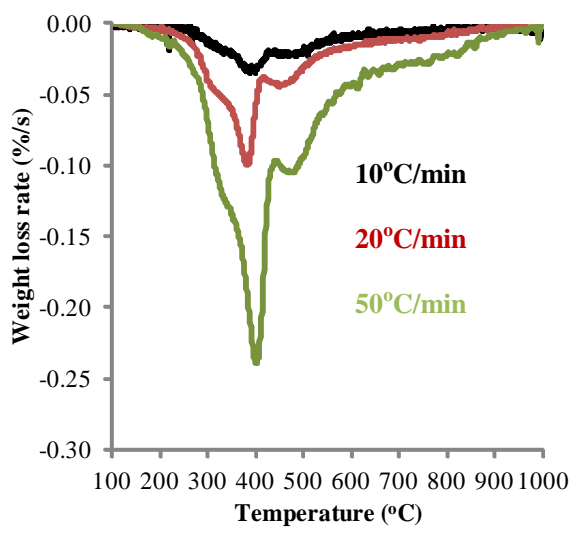

Figure 4. Weight loss rate of $20 \%$ wood in blend vs temperature at heating rates of 10,20 and $50^{\circ} \mathrm{C} / \mathrm{min}$ during co-pyrolysis.

Table 2. $\mathbf{T}_{\max }$ Final Residues, and Kinetic Parameters for CoPyrolysis of $10 \%$ Wood in Blend

\begin{tabular}{lccc}
\hline Heating rate $\left({ }^{\circ} \mathrm{C} / \mathrm{min}\right)$ & 10 & 20 & 50 \\
\hline Tmax $\left({ }^{\circ} \mathrm{C}\right)$ & $406 \pm 1$ & $380 \pm 4$ & $399 \pm 2$ \\
\cline { 2 - 4 } Final residues $(\mathrm{db} \%)$ & $53.1 \pm 1.3$ & $53.4 \pm 1.1$ & $53.2 \pm 0.6$ \\
\cline { 2 - 4 } $\mathrm{E} 1(\mathrm{cal} / \mathrm{mol})$ & 1841 & 9154 & 8341 \\
$\mathrm{~A} 1\left(\mathrm{~s}^{-1}\right)$ & $0.0005 \pm 0.0001$ & $0.101 \pm 0.016$ & $0.116 \pm 0.019$ \\
\cline { 2 - 4 } $\mathrm{E} 2(\mathrm{cal} / \mathrm{mol})$ & 6841 & 14154 & 13341 \\
$\mathrm{~A} 2\left(\mathrm{~s}^{-1}\right)$ & $0.0486 \pm 0.0069$ & $43.334 \pm 4.674$ & $37.716 \pm 3.096$ \\
\hline
\end{tabular}

Modeling fitting and Kinetic Parameters of coal, wood and their blends pyrolysis. Single first order reaction (SFOR) kinetic model ${ }^{4 \mathrm{~b}}$ and competitive two step reaction (CTSR) model that two single first order reactions (SFOR) take place simultaneously are selected to fit the experimental data. The two kinetic models can be described as following equations of SFOR (1) and CTSR (2).

$\frac{d V(t)}{d t}=A \exp \left(\frac{-E}{R T}\right)\left(V^{\infty}-V(t)\right)$

where $V(t)$ is the instantaneous volatiles yield; $V^{\infty}$ is the ultimate volatiles yield (obtained from experiment weight loss data); $A$ is a frequency factor, and $E$ is an apparent activation energy; $R$ is the universal gas constant and $T$ is the sample temperature in $\mathrm{K}$. $\frac{d V(t)}{d t}=\left\{\alpha A_{1} \exp \left(\frac{-E_{1}}{R T}\right)+(1-\alpha) A_{2} \exp \left(\frac{-E_{2}}{R T}\right)\right\}\left(V^{\infty}-V(t)\right)$

where $A_{1}$ and $A_{2}$ are frequency factors for reaction $R_{1}$ and $R_{2}$ respectively; $E_{1}$ and $E_{2}$ are apparent activation energy for reaction $R_{1}$ and $R_{2}$ respectively; and $\alpha$ is the fraction of volatile matter participating into reactions.

SFOR kinetic model was used to obtain $E$ and $A$ by taking natural $\log$ of equation 1 and fitting to straight line using the experimental data including the maximum weight loss rate. For CTSR, it was assumed that $E_{1}=E$ from the SFOR, and $E_{2}=E+5000$ $\mathrm{cal} / \mathrm{mol}$ and $\alpha=0.5$. Then Generalized Reduced Gradient nonlinear solver that minimizes the error between the predicted and experimental weight loss with respect to $A_{1}$ and $A_{2}$. Figure 5 shows the experimental and predicted weight losses by CTSR models with respect to temperature for $10 \%$ wood in blend. The kinetic parameters for the blend from CTSR are listed in Table 2 at 10, 20 and $50^{\circ} \mathrm{C} / \mathrm{min}$ heating rates. SFOR model failed to replicate the experimental weight loss exactly in all tests of the coal and wood blends. CSTR model fits well with experiment weight loss data.

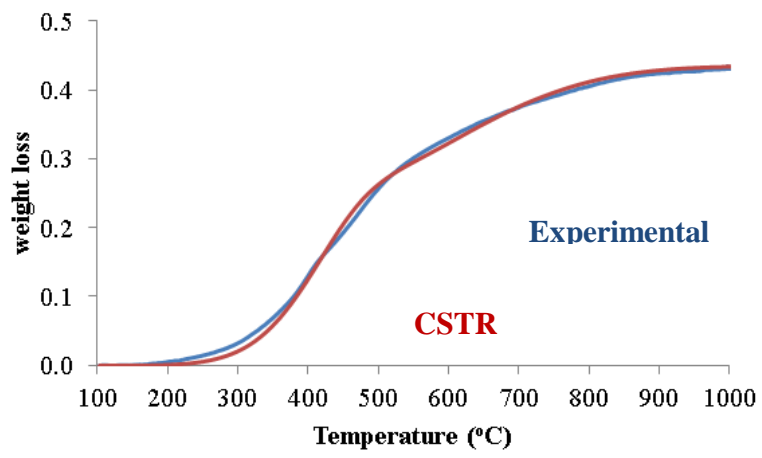

Figure 5. Weight loss vs temperature of experimental and predicted by two step reactions (CSTR) models for $10 \%$ wood in blends at the heating rate of $50^{\circ} \mathrm{C} / \mathrm{min}$.

\section{Conclusions and Future work}

Differences in thermal behavior and reactivity in co-pyrolysis of Powder River Basin (PRB) sub-bituminous coal and pelletized southern yellow pine wood sawdust blends at low heating rates are observed. Coal/wood blends have higher reactivity compared to coal alone in the lower temperature due to the high volatile matter content of wood. As heating rates increase, weight loss rates increase. The experiment data obtained from TGA has a better fit with proposed two step first order reactions model compared single first order reaction model. This is an ongoing study. Experiments at higher heating rates and different type of coal and biomass blends will be performed, and the kinetic model will be further developed.

\section{References}

(1) (a) Hein, K. R. G.; Bemtgen, J. M., EU clean coal technology - cocombustion of coal and biomass. Fuel Processing Technology 1998, 54 (1-3), 159-169; (b) Hughes, E. E.; Tillman, D. A., Biomass cofiring: status and prospects 1996. Fuel Processing Technology 1998, 54 (1-3), 127-142.

(2) Skone, T. J. Role of alternative energy sources:pulverized coal and biomass co-firing technology assessment; DOE/NETL: 2012.

(3) Ozawa, T., Thermal analysis - review and prospect. Thermochimica Acta 2000, 355 (1-2), 35-42.

(4) (a) Antal, M. J.; Varhegyi, G., Cellulose pyrolysis kinetics - the current state knowledge. Industrial \& Engineering Chemistry Research 1995, 34 (3), 703-717; (b) Branca, C.; Albano, A.; Di Blasi, C., Critical valuation of global mechanisms of wood devolatilization. Thermochimica Acta 2005, 429 (2), 133-141. 